\title{
AVALIAÇÃO DO PROCESSO DE ELETRODEPOSIÇÃO DA LIGA METÁLICA Ni-Cu USANDO CORRENTE PULSADA
}

\section{Thales A. Amarante, Thayane C. M. Nepel, Ambrósio F. de Almeida Neto}

\section{Resumo}

O trabalho consistiu na síntese de ligas $\mathrm{Ni}-\mathrm{Cu}$ por eletrodeposição sob corrente pulsada, para avaliar a influência da concentração de níquel, do pH e da corrente elétrica, na eficiência de eletrodeposição, composição e características da liga. A eletrodeposição ocorreu sobre um substrato de cobre e foi utilizado um banho eletrolítico com sulfatos de cobre e de níquel e citrato de amônio como complexante. As ligas foram analisadas por MEV e EDX e obteve-se uma liga com concentração próxima a da liga comercial Monel-200, com eficiência de eletrodeposição de $81 \%$.

\section{Palavras-chave: Eletrodeposição, Níquel, Cobre}

\section{Introdução}

A síntese de materiais nanoestruturais por eletrodeposição tem recebido grande interesse nos últimos anos (Baskaran, et al, 2015), pois esses materiais podem substituir revestimentos obtidos de Cromo, material considerado prejudicial ao ambiente, mutagênico e carcinogênico (CETESB, 2009). Nesse sentido, a liga de níquel e cobre se destaca por suas propriedades magnéticas e térmicas, resistência à corrosão e aplicação decorativa (Alper et al., 2008). A obtenção dessa liga por eletrodeposição por corrente pulsada tem se mostrado eficiente para obter maior resistência à corrosão (Gosh et al., 2000). Com isso, o objetivo desse trabalho foi avaliar a influência dos parâmetros operacionais na eficiência de eletrodeposição e nas características das ligas. Os resultados obtidos poderão ser úteis para a recuperação de metais, de resíduos industriais, pela formação de um material com valor comercial.

\section{Resultados e Discussão}

A pesquisa seguiu um planejamento fatorial de $2^{3}$ com 3 experimentos no ponto central, variando a concentração de níquel no banho eletrolítico, o pH e a corrente elétrica (Tabela 1). As eletrodeposições ocorreram sobre placas de cobre, de $8 \mathrm{~cm}^{2}$ de área e com corrente pulsada. As eficiências e composições obtidas pela análise de EDX são apresentadas na Tabela 2.

Tabela 1. Níveis do planejamento

\begin{tabular}{lccc}
\hline \multicolumn{1}{c}{ Níveis } & -1 & 0 & +1 \\
Variáveis & 2,0 & 5,5 & 9,0 \\
$\mathrm{pH}$ & 0,030 & 0,065 & 0,100 \\
$\mathrm{C}_{\mathrm{Ni}}(\mathrm{mol} / \mathrm{L})$ & 200 & 400 & 600 \\
$\mathrm{I}(\mathrm{mA})$ & & & \\
\hline
\end{tabular}

Tabela 2. Composição e eficiência da deposição

\begin{tabular}{ccccccc} 
Exp & $\mathrm{C}_{\mathrm{Ni}}$ & $\mathrm{pH}$ & $\mathrm{I}$ & $\begin{array}{c}\mathrm{Ni} \\
(\% \mathrm{~m})\end{array}$ & $\begin{array}{c}\mathrm{Cu} \\
(\% \mathrm{~m})\end{array}$ & $\begin{array}{c}\text { Eficiência } \\
(\%)\end{array}$ \\
1 & -1 & -1 & -1 & 0,00 & 100,00 & 81,83 \\
2 & +1 & -1 & -1 & 0,00 & 100,00 & 78,46 \\
\hline 3 & -1 & +1 & -1 & 0,38 & 99,62 & $-3,38$ \\
4 & +1 & +1 & -1 & 5,33 & 94,67 & 14,41 \\
5 & -1 & -1 & +1 & 0,73 & 99,27 & 21,67 \\
6 & +1 & -1 & +1 & 1,71 & 98,29 & 25,06 \\
7 & -1 & +1 & +1 & 62,67 & 37,33 & 57,38 \\
8 & +1 & +1 & +1 & 62,52 & 37,48 & 81,04 \\
$9(\mathrm{C})$ & 0 & 0 & 0 & 0,67 & 99,33 & 37,57 \\
$10(\mathrm{C})$ & 0 & 0 & 0 & 0,67 & 99,33 & 36,72 \\
\hline $11(\mathrm{C})$ & 0 & 0 & 0 & 0,67 & 99,33 & 38,41 \\
\hline
\end{tabular}

De forma geral, a eficiência tende a aumentar com o aumento dos níveis das variáveis (Exp 8). Uma boa eficiência também foi obtida no menor nível das variáveis (Exp 1), mas isso forçou a eletrodeposição do cobre metálico, enquanto ao utilizar os níveis máximos é possível obter a liga metálica desejada, com a eficiência de $81 \%$. A composição obtida no experimento 8 se assemelha à liga comercial Monel, reconhecida por sua alta resistência à corrosão. Esta composição também foi obtida no Exp 7. Uma comparação entre as ligas dos Exp 7 e 8 pode ser observada na Figura 1, mostrando que a liga do Exp 8 apresentou maior uniformidade e homogeneidade.

Figura 1. Microscopias dos experimentos 7 e 8

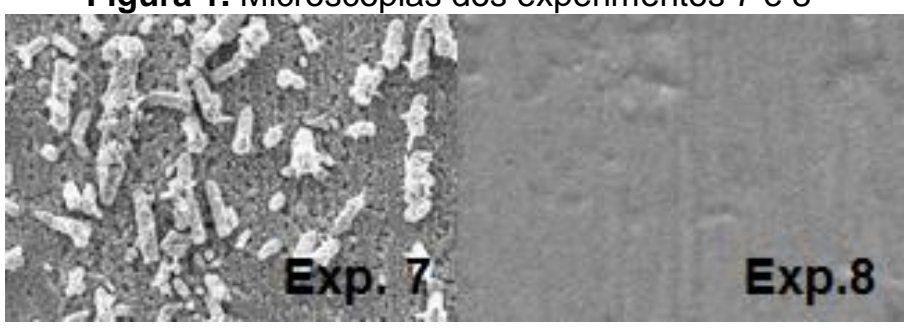

\section{Conclusão}

Os parâmetros que permitiram a maior eficiência de deposição e obtenção de uma liga com a composição desejável, próxima à liga comercial Monel-400, foram os máximos níveis de $\mathrm{pH}$, concentração de níquel e corrente. Nestes parâmetros a liga se mostrou uniforme. Os resultados obtidos estabeleceram um potencial para eletrodeposição utilizando resíduos industriais, garantindo assim o tratamento do resíduo em conjunto com a obtenção de um material de valor comercial.

\section{Agradecimentos}

Ao CNPq pelo auxilio financeiro.

ALPER, M.; KOCKAR, H.; SAFAK, M.; BAYKUL, C. Comparison of Ni-Cu alloy films electrodeposited at low and high $\mathrm{pH}$ levels. Journal of Alloys and Compounds, v. 453, p. 15-19, 2008.

BASKARAM, I.; SANKARA, T. S. N.; STEPHEN, A. Pulsed electrodeposition of nanocrystalline $\mathrm{Cu}-\mathrm{Ni}$ alloy films and evaluation of their characteristic proprieties. Materials Letters, v. 60, p. 1990-1995, 2006 CESTESB. Qualidade das águas no interior do estado de São Paulo. Séries de Relatórios, Apêndice A. São Paulo, 2009, p.9.

GHOSH, S. K.; GROVER, A. K.; DEY, G. K.; TOTLANI, M. K Nanocrystalline $\mathrm{Ni}-\mathrm{Cu}$ alloy plating by pulse electrolysis. Surface and Coatings Technology, v. 126, p. 48-63, 2000. 